The University of Maine

DigitalCommons@UMaine

Library Staff Publications

Fogler Library

$7-2018$

\title{
Play On? Comparing Active Learning Techniques for Information Literacy Instruction in the Public Speaking Course
}

Jennifer Bonnet

University of Maine, Fogler Library, jenbonnet@maine.edu

Liliana Herakova

University of Maine, Communication and Journalism, liliana.herakova@maine.edu

Ben McAlexander

Trihydro Corporation, bmcalexander@yahoo.com

Follow this and additional works at: https://digitalcommons.library.umaine.edu/lib_staffpub

Part of the Communication Commons, and the Library and Information Science Commons

\section{Repository Citation}

Bonnet, Jennifer; Herakova, Liliana; and McAlexander, Ben, "Play On? Comparing Active Learning Techniques for Information Literacy Instruction in the Public Speaking Course" (2018). Library Staff Publications. 29.

https://digitalcommons.library.umaine.edu/lib_staffpub/29 


\title{
Play On? Comparing Active Learning Techniques for Information Literacy Instruction in the Public Speaking Course
}

\author{
By Jennifer Bonnet, Liliana Herakova, and Benjamin McAlexander
}

(manuscript accepted for publication in The Journal of Academic Librarianship, Volume 44, Issue 4, July 2018, Pages 500-510)

\section{Introduction}

In the current social and political context, developing information literacy competencies is seen as central to ensuring critical civic participation in democratic processes (Rutenberg, 2016; Smith, 2013). Actively engaging students with information literacy instruction is the foundation of the Association of College \& Research Libraries' (relatively new) Framework for Information Literacy. Yet, missing from the library literature are studies that examine the effectiveness of one active learning approach versus another. This paper reports on a research project that aimed to do just that. We used two discrete active learning techniques to teach information literacy concepts in a Public Speaking course and compared the effectiveness of the techniques in facilitating learning outcomes. The current article reports on a subset of data that is part of a larger research project assessing learning outcomes in information literacy, public speaking competencies, and civic engagement attitudes. Questions that guided this particular part of the research included: 1) Does the type of active learning technique make a difference in students' information literacy gains? 2) Does it make a difference who facilitates information literacy instruction in the Public Speaking class (librarian or class instructor)?

Critical Communication Pedagogy (CCP; Fassett \& Warren, 2007) informed the current study, the interventions it tested, and their overall integration in the course design. CCP centers students' active problem-posing participation in the learning process from a dialogic perspective that sees the classroom as a space for the co-production of knowledge. Particularly with regards to information literacy, such a framework is helpful, since most people evaluate, interpret, and use information based on their contextual knowledge, beliefs, and needs. From a CCP perspective, active learning approaches to information literacy instruction are not simply more engaging or entertaining, they produce more critical learning by allowing individuals and groups to reflect on factors that shape their interaction with and understanding of information.

In the sections that follow, we first explain the rationale for the study, focusing on information literacy and communication education. We then describe the study design, including data collection and analysis methods and the characteristics of the participants in the current study. We conclude the article with a summary and discussion of the results, suggesting directions for further research.

Information Literacy

\section{Literature Review}

Amidst the proliferation of "fake news" stories (Fisher et al., 2016; Rutenberg, 2016; Shao et al., 2017) and in a "post-truth" political climate (Higgins, 2016; Oxford Dictionaries, 2016), it is concerning that while students demonstrate a savviness for social media use and Internet navigation, they continue to be easily misled when determining if online information is credible, 
deceptive, or entirely fabricated (Stanford History Education Group, 2016). Such trends have resulted in calls for greater information literacy instruction, further scrutiny of educational priorities (Jazynka, 2017), and new lesson plan designs (Benjes-Small \& Dunn, 2017; Bowden, 2017; Fake News, 2017). In this social and educational context, it is clear that a need for information literacy instruction, particularly with a focus on source evaluation, remains paramount.

Information literacy (IL) is "the set of integrated abilities encompassing the reflective discovery of information, the understanding of how information is produced and valued, and the use of information in creating new knowledge and participating ethically in communities of learning" (Association of College and Research Libraries, 2015, n.p.). This definition emphasizes reflexivity, deconstruction and construction of information, the creation of new knowledge - and all with the purpose of enhancing and promoting ethical civic participation. Seen in such a way, IL instruction aligns closely with the commitments and praxis of critical communication pedagogy (CCP; Fassett \& Warren, 2007), which are addressed in more detail in the next section.

\section{Critical Information Literacy and Communication Education}

Although the effort to develop critical information literacy instruction is multidisciplinary (Riehle \& Weiner, 2013; Simmons, 2005; Smith, 2013), it is especially important in the field of Communication. Critically assessing messages and using information in an ethical way are two of the major Learning Outcomes in Communication, according to the National Communication Association (2015). Information literacy has traditionally been emphasized in the field of communication education and especially in public speaking courses, where the study of accessing and using existing information to provide quality "proof" traces its history to Aristotle's Rhetoric. Furthermore, public speaking is a required course for many students and on many campuses across the U.S., regardless of major. Thus, the course itself provides a suitable context for integrated information literacy instruction - both in terms of disciplinary fit and in terms of fostering foundational competencies across the curriculum.

Within the last decade, work within both the fields of Information and Library Sciences and Communication has more intentionally turned to critical pedagogy as a method and a purpose for information literacy and communication instruction (e.g., Elmborg, 2006; Fassett \& Warren, 2008). Recognizing that how a topic is taught is never neutral, Elmborg (2006) argues for information literacy instruction that develops students' critical consciousness by not simply teaching research stages and skills, but by engaging students with current social problematics and the active production of knowledge. Fassett and Warren $(2007 ; 2008)$ similarly propose critical communication pedagogy (CCP) that moves away from "a seemingly apolitical, neutral, 'just the facts' approach to teaching and learning, one that divorces knowledge from context, to an embodied, intellectual commitment to communication as constitutive" (Fasset \& Warren, 2008, p. 7). In CCP, communication (including research activities of seeking and assessing information) is not simply a process of encoding and transmitting representations of social facts, nor are humans passive recipients of such transmissions. Instead, communication is an active, dialogic process of co-creating and acting in relation to social realities. 
From a CCP perspective, IL instruction becomes much more than guiding students through stages of topic identification and finding a "good" source to support pre-existing ideas and opinions, as suggested in more traditional models of IL instruction (e.g., Keene, Colvin, \& Sissons, 2010). Instead, continuously developing IL becomes one way to critically examine the mediated construction of reality and of our assumptions as consumers and creators of informative and persuasive messages. For example, in the public speaking course that provided the context for the present study, information literacy instruction is integrated in a semester-long process of community exploration. Students work together to identify contentious issues in the community, research and present diverse perspectives on the issues, formulate positions, facilitate civil dialogues, and develop policy persuasive speeches that seek to create a change in regards to the identified issues. In the course of the semester, students repeatedly engage and practice information literacy to consider what matters in their communities, what knowledge exists about what matters, and how students' own existing beliefs and experiences both shape and are shaped by the information that is sought and accessed.

In its integrated design, the larger project of which this study is a part seeks to contribute to research on and applications of information literacy frameworks within Communication. Existing work in this area ranges from high-level discussions of ways to conceptualize information literacy instruction within a communication curriculum (Gersch et al., 2016; McCall \& Ellis, 2017; Rustic \& Wood, 2017) to actual, curriculum-integrated models that demonstrate the value of pairing information literacy with communication instruction (Herakova, Bonnet, \& Congdon, 2017; Hunt, Simonds \& Simonds, 2009; Meyer, Hunt, Hopper, Thakkar, Tsoubakopoulos, \& Hoose, 2008; Nielson \& Jetton, 2014; Weaver \& Pier, 2010; Sjoberg \& Ahlfeldt, 2010). Most often in the form of case studies, such research presents strategies for improving students' ability to critically assess and use information through various interventions or instructional methods (e.g., librarian-aided course design; multiple, short research sessions rather a standalone workshop; extracurricular consultations with librarians). However, there is little in this literature that compares or contrasts pedagogical approaches to information literacy instruction itself - in other words, there is a dearth of assessment of what works when teaching information literacy specifically.

There are some notable exceptions. Meyer et al. (2008) investigated the intensity of information literacy instruction provided to undergraduates in face-to-face sessions (i.e., whether or not the number of contacts with a librarian made a difference in information literacy outcomes). Using a pre- and post-test design focused on locating and citing information, they identified gains in information literacy scores for students who had more frequent interactions with a librarian. Hunt et al. (2009) tested passive versus active approaches to teaching information literacy in face-toface classroom interactions and found that students in the latter group showed statistically significant improvement in information literacy measures over time. These contributions further our understanding of the potential for developing information literacy in the communication classroom, and the latter highlights a growing pedagogical emphasis on active learning as a valuable method for critical teaching and learning.

Active Learning Approaches to Information Literacy Instruction Debates about the effectiveness of various types of instructional delivery are available ad infinitum. In recent decades, active, student-centered learning has been emphasized across the 
college curriculum (Bonwell, 1991; Faust \& Paulson, 1998; Prince, 2004). Defined as "student activity and engagement in the learning process" (Prince, 2004, p. 1), active learning is often positioned in opposition to "passive learning." The latter is typically characterized by lecturebased instruction and suggests that learning primarily occurs when knowledge is passed from instructor to student. Examples of active learning, on the other hand, include writing exercises and reflections, debates and dialogues, role playing, problem-based learning, simulations, and small and large group discussions. Potential benefits of active learning include increased retention of educational content (Prince, 2004), better scores on tests (Freeman et al., 2014; Prince, 2004), an increase in positive attitudes toward learning (Prince 2004), and enhanced critical thinking skills (Faust \& Paulson, 1998).

In this environment, calls for active learning in the library classroom have gained momentum. These include everything from general recommendations for student engagement in one-shot sessions (Walsh \& Inala, 2010) to concrete approaches to active learning, like problem-based learning (Wenger, 2014), flipped classrooms (Benjes-Small \& Tucker, 2013; Khailova, 2017), and inquiry-based pedagogies (Rockenbach, 2011). One active learning exercise that has gained popularity in recent years is the use of games in the college classroom, and the library is no exception. ${ }^{1}$ However, evidence of the impact of active learning on information literacy instruction has been mixed (see Koufogiannakis \& Wiebe (2006) for a systematic review). More recent attempts at discerning the merits of active learning in library instruction have tested specific, active interventions alongside more passive instruction (e.g., a lecture or database demonstration). Such research suggests that active learning may have some advantages, such as: reducing anxiety when students consult library resources, enhancing perceptions of the usefulness of librarians, more efficient searching, and greater use of librarian assistance (Detlor \& Sorenko, 2012); improving the quality of students' research outputs (Johnson \& Barrett, 2017), and augmenting students' searching and citation skills (Tewell \& Angell, 2015).

Despite the many suggestions for ways to incorporate active learning into information literacy instruction (including the recently developed Framework for Information Literacy Toolkit from the Association of College \& Research Libraries), ${ }^{2}$ and alongside a growing emphasis on gamification as the 'next big thing,' there is a dearth of research that compares the educational merits of one active learning technique versus another. Thus, it is unclear how beneficial certain types of active learning approaches may be with regards to facilitating the development of particular learning outcomes. Responding to this need, this study examined and compared two distinct active learning approaches to teaching information literacy.

\section{Research Context}

\section{Methodology}

Every semester, nearly 500 students take a Fundamentals of Public Communication course at [a medium-sized public university in the Northeastern U.S.], with most students enrolling to fulfill a general education requirement. As in most basic communication courses in the U.S., the focus

\footnotetext{
${ }^{1}$ See Margino (2013) for a review of in-person and online games in information literacy instruction; see Tewell \& Angell (2015) for a study of online games in information literacy learning; see Young (2016) for a review of the potential advantages of games and gamification for information literacy learning; and see Hoppe's presentation on play in the library (2017) that inspired part of the methodology in this research project.

${ }^{2}$ See Free (2017) and Oakleaf (2014).
} 
is on public speaking (Valenzano III, Wallace, \& Morreale, 2014). In addition, however, this course aims to develop a foundational understanding of communication as critical engagement with people, communities, and messages (Fassett \& Warren, 2007). Thus, information literacy is a key component of the course, integrated throughout the curriculum (instead of limited to a few class sessions). The curriculum integration of information literacy learning was accomplished through an intentional and sustained course-library partnership, where students have multiple opportunities to work with a librarian as they are developing and researching speeches. The partnership supports student learning and performance in areas that are common in basic course curricula across institutions, such as conducting research in preparation for informative and persuasive speech assignments.

\section{Participants and Recruitment}

Participants in this study included students enrolled in the Fundamentals of Public Speaking course at the [university name] during the Fall 2017 semester. There were a total of 426 participants. Participant ages ranged from 18 to 42 , with a median age of 20 . Nearly $67 \%$ of participants identified as male $(n=285)$ and $32 \%$ as female $(n=137)$; four participants did not identify with a gender. In terms of race/ethnicity, participants identified overwhelmingly as White $(88 \% ; \mathrm{n}=375)$ with the all other identifications as follows: Not specified $=3.5 \%(15)$, Hispanic/Latino $=4.5 \%(19)$, American Indian/Alaska Native $=0.2 \%(1)$, Black/African American $=1.6 \%(7)$, Asian $=1.9 \%(8)$, Hispanic/Latino \& White $=0.2 \%$ (1). Participants were divided into three "conditions" prior to the start of the semester. There were two experimental groups: Group A with 7 sections of 136 students total and Group B, which included 8 sections of 158 students total. This study also included a control group (Group C) of 7 sections with 132 students total. Sections were randomly assigned to each group. Demographic characteristics of the three different groups were comparable (see Table 1).

The authors submitted their research proposal to the Institutional Review Board (IRB) for approval and were granted an exemption. Special recruitment efforts were not needed since, upon IRB approval, assessment occurred as part of on-going educational activities in the class and, thus, all enrolled students were participants. Information about the project, its goals, and about students' voluntary participation was provided at the beginning of each assessment measure, allowing students to decide if they would like to complete the surveys or not.

Students received participation points for their involvement in this research. A statement was placed in each section's syllabus, informing students of the project, their participation in it, and that their responses to survey items would not affect their grades beyond receiving participation credit. The researchers were available to visit sections upon request and to answer any questions in person, via e-mail, or phone. Instructors administered assessment measures as part of regular classroom activities and/or assigned homework. No information on students' performance was shared with instructors prior to entering final semester grades.

\section{Data Collection Procedure}

Data were collected via Qualtrics before and after a scheduled library session. The library instruction session aimed to develop students' critical thinking skills related to information literacy and speech research, with a specific focus on determinants of credibility and suitability of source selection. To assess the effectiveness of the library instruction session, students 
completed pre- and post-session surveys in all assigned groups. The pre-session survey was administered by the instructors in the class period preceding the library session. The post-session survey was administered by the librarian leading the session at the end of it. Students in the control group were provided a research session designed by the section instructor and completed the pre- and post-test surveys in-class, following the same schedule as the sessions receiving library instruction.

The 15 classes that received information literacy instruction from a librarian visited the library at two points during the semester. However, only one visit was included in the study and subsequent analysis. One librarian provided all instruction to Groups A and B. Five instructors provided instruction to the other seven sections (Group C).

The study's primary goal was to understand whether a particular type of information literacy instruction would make a difference in students' learning, as measured by the post-test survey. To this end, in the Fall of 2017, each Fundamentals of Public Communication section (22 sections total) was randomly assigned to one of three groups: Library Instruction Method A (Group A), Library Instruction Method B (Group B), or No Library Instruction Method (control group; Group C). As noted previously, critical communication pedagogy emphasizes that communication is a participatory process of shared learning that acts upon social realities, which the instructional methods in this study attempted to reflect.

Library Instruction Method A consisted of the following:

- Large group discussion of ways to take a familiar topic and turn it into various types of speeches;

- Small group evaluation of two websites on a related topic to determine elements of credibility, followed by large group discussion;

- Large group discussion of ways various resources might answer questions students have on their speech topics; and a brief demonstration of strategic approaches to finding some of these sources.

Library Instruction Method B consisted of the following:

- Large group discussion of ways to take a familiar topic and turn it into various types of speeches;

- A play exercise in the vein of 'hot potato' in which students gathered in a circle and tossed a beach ball to one another while music played in the background. ${ }^{3}$ When the music stopped, the person with the ball in hand started a conversation with the class about a resource listed on the ball (e.g., Tweet, Wikipedia article, New York Times article, journal article), ways they might determine the credibility of those sources in preparation for their speeches, and how each resource might answer questions they have on their topics. Question prompts were provided to start these conversations.

- A brief demonstration of strategic approaches to finding some of the sources discussed in the 'hot potato' game.

\footnotetext{
${ }^{3}$ Adapted from Hoppe, 2017
} 
Library Instruction in Group C was based on instructor choice for those seven research sessions. The majority of instructors in this group had observed the librarian's information literacy sessions in previous semesters and either drew on that experience and the associated materials (like the online course guide), or on prior experience with library research in their individual academic programs. There was not a routine approach to this group's instruction.

\section{Instrument Development}

The authors developed an information literacy instrument that addressed key competencies within [university name's] Foundations of Public Speaking course, specifically source credibility and the capacity for a source to address students' topics and/or answer their research questions. Students often struggle with choosing sources that can answer questions or deepen understanding about their topics (i.e., relevance), such as news articles or social media posts for firsthand accounts, journal articles for studies on specific scholarly strands of their topics, or books for broader treatments of an issue. Further, deciding on what might lend credibility to a piece of information can cause confusion. Students struggle with defining currency (and whether or not that matters in the context of a speech topic) or expertise (such as the type of credentials an author has).

A pre-/post-test design was used to test a specific intervention (i.e., type of information literacy instruction) and the extent to which it affected gains in student learning on a specific topic (i.e., source selection and evaluation). In an effort to align the pre- and post-tests with course requirements, questions were placed in the context of a familiar scenario within the course: preparing a speech on a topic of interest using credible sources. Our intention was to create questions that tested comprehension and application, which is why questions were mirrored rather than repeated. The survey instrument included Likert-scale questions and open-ended questions asking students to respond to research scenarios in connection with their public speaking class. These scenarios grew out of elements emphasized in the course with regards to information literacy. The authors developed the instrument with inspiration drawn in part from Madonna University's information literacy assessment, ${ }^{4}$ elements of credibility assessment associated with the CRAAP ${ }^{5}$ test, and key learning outcomes for the course. ${ }^{6}$ All students took the same pre- and post-tests, and in the same order. See the Appendix for a list of the pre- and post-test questions that are included in this analysis, a discussion of two questions that were developed but then excluded from analysis, and the evaluation concepts that were considered in the development of the measures.

\section{Data Analysis}

Table 1 - A, B, C with Class, Previous Sessions

Table 2 - ANOVAs on pre-test

Table 3 - t-test on pre-test versus post-test results (grouped by treatment)

Table 4 - ANCOVA on post-test with pre-test as covariate and treatment as factor

Table 5 - t-tests on pre-test versus post-test results by class

\footnotetext{
${ }^{4}$ http://library.madonna.edu/pages/InfoLitPostTest/GeneralForm.cfm

5 Meriam Library, 2010

${ }^{6}$ One open ended question on each test asked students to write about their reasoning in relation to a decision they had to make and how they would approach certain tasks in relation to information literacy and/or public speaking. This paper includes quantitative analysis only. Future analysis will incorporate the open-ended questions.
} 
Figure 1 - ANOVA pre-test with class as group

Figure 2 - Pre-test versus post-test scores (grouped by treatment)

Figure 3 - Pre-test versus post-test scores (grouped by class)

Student scores on the pre- and post-tests were calculated as percentages of correct answers on Questions 2-9 (see the Appendix).

Student test outputs were grouped by treatment (groups A, B, and C) for analysis of pre-test and post-test scores. Students who did not take both the pre-test and post-test were excluded from the sample groups and data analysis.

To assess differences in baseline information literacy, the pre-test scores were subjected to a oneway analysis of variance (ANOVA) for various groupings. An ANOVA tests whether means for groups are equal. For this study, the means tested were for three sets of pre-test scores: treatment (A, B, and C (control)), class level (First year, Sophomore, Junior, Senior), and previous number of library sessions. A Tukey Kramer post hoc analysis was conducted for tests that indicated significant differences between groups. This identified specific groups that were likely to have unequal mean pre-test scores. Homogeneity of variances was confirmed on the three ANOVAs with a Levene test.

Table 1. Characteristics for Students in Treatment Groups A, B, and C

\begin{tabular}{|c|c|c|c|c|c|c|c|c|c|c|c|}
\hline \multirow[b]{2}{*}{ Treatment } & \multirow[b]{2}{*}{ Description } & \multirow[b]{2}{*}{$\begin{array}{c}\text { Sample } \\
\text { Size }\end{array}$} & \multicolumn{4}{|c|}{ Class Level } & \multicolumn{5}{|c|}{ Number of Previous Library Sessions } \\
\hline & & & $\begin{array}{l}\text { First } \\
\text { Year }\end{array}$ & Sophomore & Junior & Senior & 1 & 2 & 3 & 4 & 5 \\
\hline A & Lecture & 136 & 64 & 36 & 27 & 9 & 90 & 27 & 12 & 6 & 1 \\
\hline B & Play & 158 & 79 & 47 & 24 & 8 & 113 & 24 & 10 & 3 & 8 \\
\hline C & Control & 132 & 68 & 26 & 27 & 11 & 88 & 24 & 10 & 6 & 4 \\
\hline All Groups & & 426 & 211 & 109 & 78 & 28 & 291 & 75 & 32 & 15 & 13 \\
\hline
\end{tabular}

\begin{tabular}{|c|c|c|c|c|c|c|c|c|c|c|c|c|}
\hline Treatment & Description & $\begin{array}{c}\text { Sample } \\
\text { Size }\end{array}$ & Male & Gender & $\begin{array}{c}\text { Not } \\
\text { Specified } \\
\end{array}$ & White & $\begin{array}{c}\text { Not } \\
\text { Specified }\end{array}$ & $\begin{array}{c}\text { Hispanic } / \\
\text { Latino }\end{array}$ & \begin{tabular}{|l} 
Ethnicity \\
Black / \\
African \\
American
\end{tabular} & Asian & \begin{tabular}{|c|} 
Hispanic $/$ \\
Latino \& \\
White
\end{tabular} & $\begin{array}{c}\text { American } \\
\text { Indian / } \\
\text { Alaska } \\
\text { Native } \\
\end{array}$ \\
\hline A & Lecture & 136 & 90 & 46 & 0 & 124 & 3 & 5 & 1 & 2 & 1 & 0 \\
\hline$B$ & Play & 158 & 107 & 49 & 2 & 142 & 4 & 8 & 3 & 1 & 0 & 0 \\
\hline C & Control & 132 & 88 & 42 & 2 & 109 & 8 & 6 & 3 & 5 & 0 & 1 \\
\hline
\end{tabular}

Next, the change in pre-test and post-test scores was assessed in several ways. First, pairedsample t-tests were conducted comparing pre- versus post-test means for the A, B, and C treatments separately. Second, the post-test scores were subjected to a one way ANCOVA with pre-test score as a covariate (Dugard \& Todman, 1995; van Bruekeln, 2013). The ANCOVA is similar to an ANOVA, in that it tests whether means for groups are equal. In this case, the means tested were for post-test scores for the A, B, and C treatments. The ANCOVA differs from the ANOVA in that it accounts for covariates that can affect the post-test scores for individual students. In this case, the covariate is the pre-test score; each student has a different starting point (i.e., pre-test score) that can affect the post-test score. The use of ANCOVA allows for a 
test on the adjusted (by pre-test) post-test score, which is similar to calculating a "change" score between pre- and post-test. A Tukey Kramer post hoc analysis was conducted on the adjusted (by pre-test) mean post-test scores to identify specific groups that were likely to have unequal adjusted (by pre-test) mean post-test scores. Third, paired-sample t-tests were conducted comparing pre- versus post-test means by Class.

Statistical analyses were conducted first using R Statistical Computing Platform version 3.2.5. The exception is the ANCOVA Tukey Kramer analysis, which was carried out manually because a method for conducting the analysis on adjusted (by pre-test) mean post-test scores was not readily available in the statistical platform. Statistical significance was set to alpha $=0.05$. For the t-test comparisons by treatment, the three groups correspond to an individual test threshold of 0.0167 on a Bonferroni correction. For the t-tests by class, the four groups correspond to an individual test threshold of 0.0125 on a Bonferroni correction.

\section{Results}

Pre-test scores ranged from 0 to 1.00 with an average of 0.49 and coefficient of variation (standard deviation divided by mean) of 0.37 . The ANOVA for pre-test scores based on class indicated significant differences (Table 2, Figure 1), including First year versus Junior, First year versus Senior, and Sophomore versus Senior. Overall, the trend was one of increasing pre-test score with increasing class level, with the lowest average score for first year $(0.45)$ and the highest average grade for seniors (0.63). The ANOVA for pre-test scores based on number of previous library sessions was not significant (Table 2$)^{7}$ which means that there were not significant differences in mean scores based on students' prior library instruction. This could be an indication that students did not retain previous library session information, that the previous sessions covered different material, or that students did not accurately report the number of sessions they had previously attended. Concerning the three treatment groups, the ANOVA did not identify a significant difference in pre-test scores among the groups (Table 2), indicating a comparable information literacy baseline among the three groups.

\footnotetext{
${ }^{7}$ Students were asked the following question: "How many library workshops have you attended as part of a college or university class?"
} 
Table 2. ANOVAs and Post-hoc Comparisons on Pre-test

\begin{tabular}{|c|c|c|c|c|c|c|c|c|}
\hline \multicolumn{6}{|l|}{ ANOVA } & \multicolumn{3}{|c|}{ Tukey Kramer for $\alpha=0.05$} \\
\hline Class Level & $\underline{\text { SS }}$ & df & MS & E & $\underline{p}$ & Class Level & Lower $\mathrm{Cl}$ & Upper Cl \\
\hline Between Groups & 1.038 & $\overline{3}$ & $0 . \overline{3461}$ & 11.7 & 0.0000 & First Year vs Junior & 0.0219 & 0.1539 \\
\hline Within Groups & 12.488 & 422 & 0.0296 & & & First Year vs Senior & 0.0873 & 0.2609 \\
\hline Total & 13.526 & 425 & & & & Sophomore vs Senior & 0.0580 & 0.2485 \\
\hline \multicolumn{9}{|l|}{$\begin{array}{l}\text { ANOVA } \\
\text { Number of } \\
\text { Previous Library }\end{array}$} \\
\hline & SS & $\underline{\mathrm{df}}$ & MS & $\underline{E}$ & $\mathrm{p}$ & & & \\
\hline Between Groups & $\overline{0.28}$ & $\overline{4}$ & $0 . \overline{07009}$ & $2 . \overline{2} 28$ & 0.0653 & & & \\
\hline Within Groups & 13.25 & 421 & 0.03146 & & & & & \\
\hline Total & 13.53 & 425 & & & & & & \\
\hline \multicolumn{9}{|l|}{ ANOVA } \\
\hline Treatment & $\underline{S S}$ & $\underline{\mathrm{df}}$ & $\underline{\text { MS }}$ & $\underline{E}$ & $\mathrm{p}$ & & & \\
\hline Between Groups & $0 . \overline{10} 7$ & $\overline{2}$ & $0 . \overline{05335}$ & $1 . \overline{6} 82$ & 0.1870 & & & \\
\hline Within Groups & 13.419 & 423 & 0.03172 & & & & & \\
\hline Total & 13.526 & 425 & & & & & & \\
\hline
\end{tabular}

Figure 1. Pre-test Scores by Class Level. Brackets indicate significant differences.

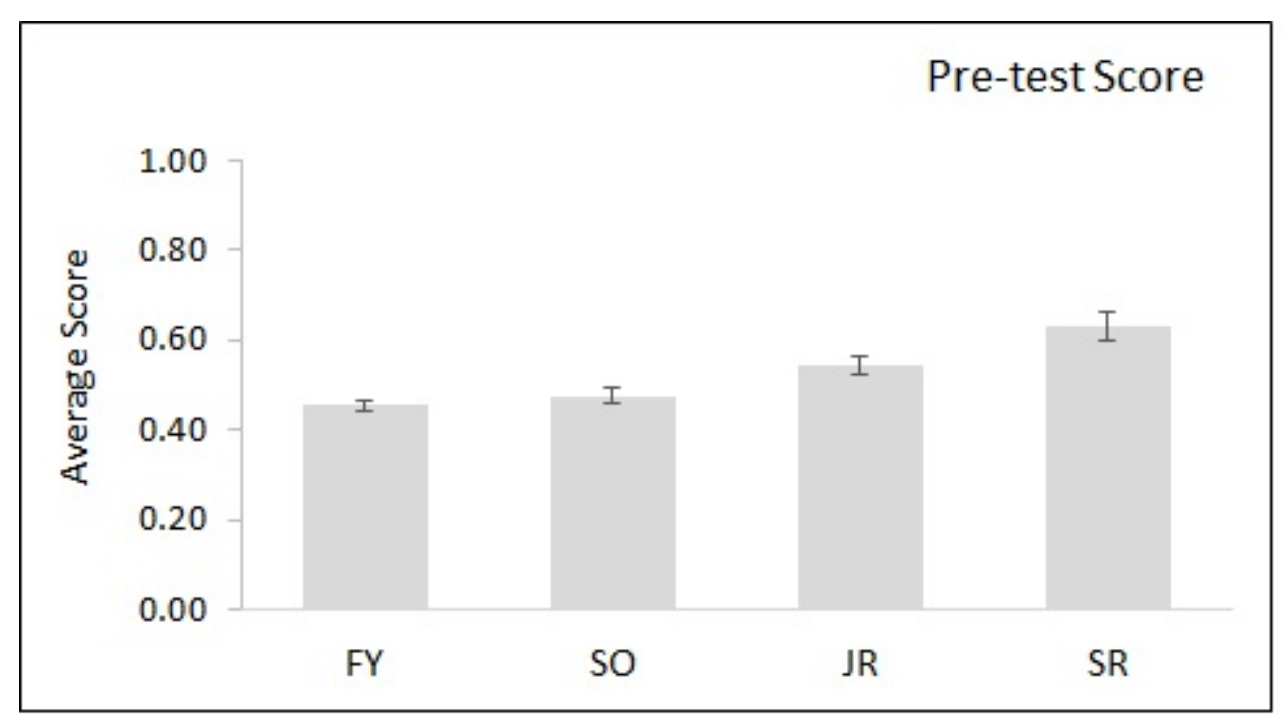

Post-test scores ranged from 0.13 to 1.00 with an average of 0.70 and coefficient of variation of 0.29. Paired-sample t-tests on pre-test versus post-test scores were significant for all three of the treatments (Table 3). To assess differences in learning between treatments, an ANCOVA for post-test scores with pre-test scores as a covariate was run (Table 4, Figure 2). Significant differences were identified between Treatments $A$ versus $C$ and $B$ versus $C$, but not $A$ versus $B$. This indicates that, when controlling for pre-test score, the two Library Instruction Methods increased post-test scores more than presentation by the class instructor (i.e., control condition). The average improvement scores for Treatments A and B were 26 and 25 percentage points respectively, while the Control group average improvement score was 14 percentage points. This 
corresponds to an effect size (Cohen's d) of approximately 0.98 and 0.88 for treatments A and B, respectively, or approximately half those values if the control group improvement score is used as baseline.

Table 3. t-test on Pre-test versus Post-test Results

$\begin{array}{lccc}\text { Treatment } & \text { Average Score } & \\ \text { A } & 0.480 & \text { Post-test } & \text { p } \\ \text { B } & 0.475 & 0.735 & 0.0000 \\ \text { C } & 0.511 & 0.722 & 0.0000 \\ \text { All Groups } & 0.488 & 0.648 & 0.0000 \\ & & 0.703 & 0.0000\end{array}$

Table 4. ANCOVA and Post-hoc Comparisons on Post-test

ANCOVA

Treatment

Pre-test

Between groups;

adjusted Post-test

Within groups;

adjusted Post-test

$\begin{array}{ccccc}\frac{\mathrm{SS}}{2.834} & \frac{\mathrm{df}}{1} & 2.8339 & 87.05 & 0.0000 \\ 0.847 & 2 & 0.4243 & 13.01 & 0.0000 \\ 13.738 & 422 & 0.0326 & & \end{array}$

Tukey Kramer for $\alpha=0.05$

$\begin{array}{ll}\text { Treatment } & \underline{Q} \\ \text { A vs C } & 6.76\end{array}$

B vs C $\quad 5.99$

Figure 2. Pre-test versus Post-test Scores based on Treatment Group

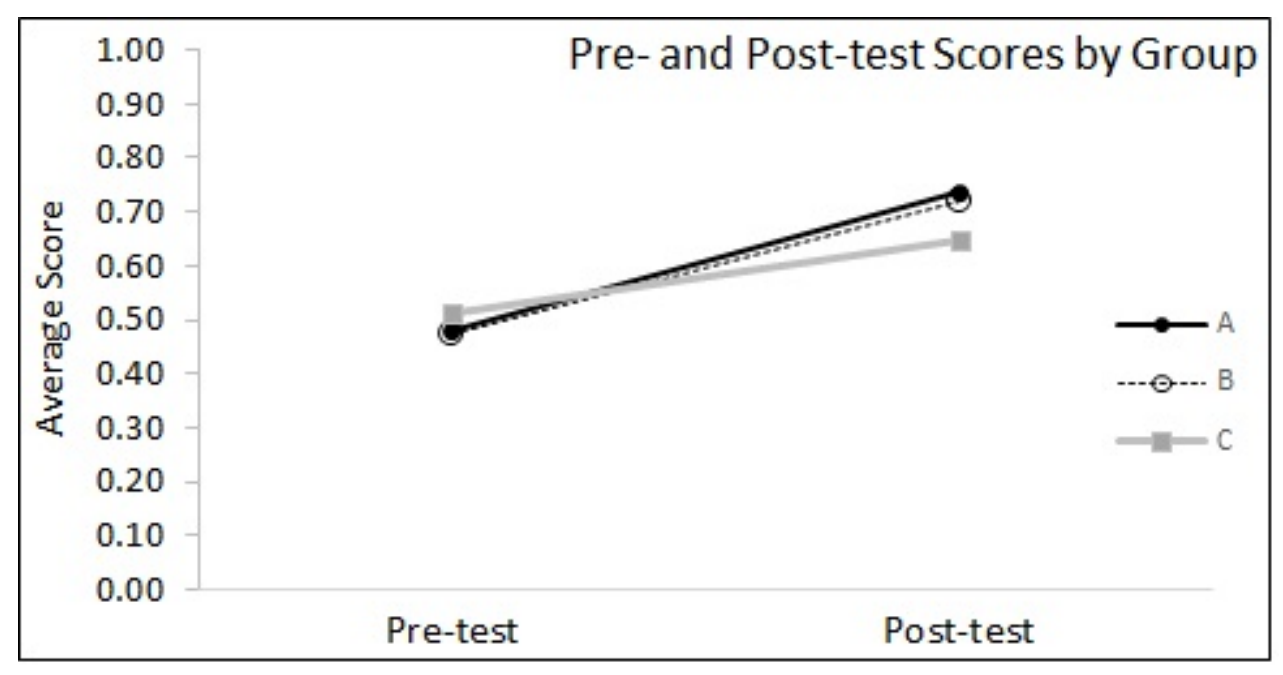

Paired-sample t-tests on pre-test versus post-test scores were significant for all four classes (Table 5; Figure 3). Each class demonstrated an improvement in average score. The magnitude of improvement decreased with class level, with First Year students improving by 21 percentage points and Seniors improving by 12 percentage points. 
Table 5 . t-tests on pre-test versus post-test results by Class

\begin{tabular}{lrcc} 
& \multicolumn{3}{c}{ Average } \\
FY & Pre-test & Post-test & $p$ \\
SO & 0.46 & 0.67 & 0.0000 \\
JR & 0.48 & 0.65 & 0.0000 \\
SR & 0.55 & 0.69 & 0.0000 \\
& 0.63 & 0.75 & 0.0002
\end{tabular}

Figure 3. Pre-test versus Post-test Scores by Class

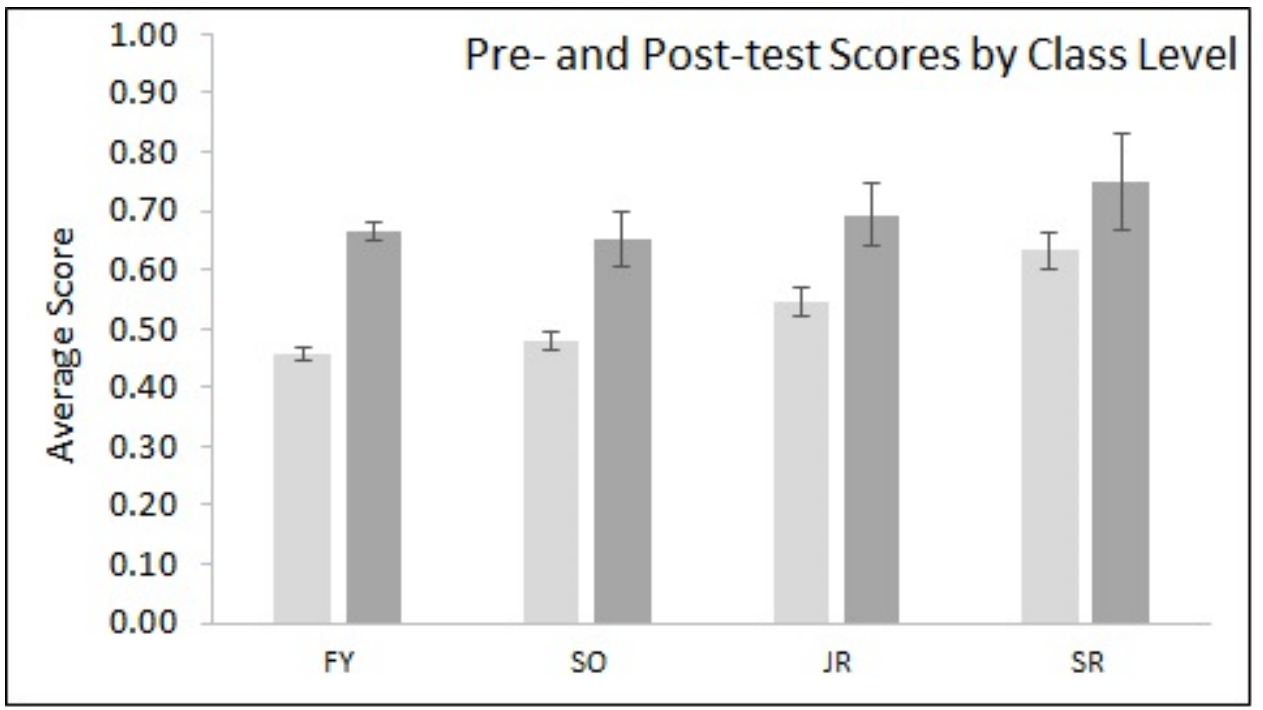

\section{Discussion}

As discussed previously, the ability to evaluate sources is important to undergraduate research and critical thinking in general, and in the field of Communication Studies in particular. Active learning has shown promise for information literacy, but little work has been done to compare types of active learning instruction. Therefore, we conducted a comparative study in an introductory public speaking course that tested two active learning approaches to information literacy instruction alongside a control group. The sample size was robust, with all three treatment groups comprising greater than 130 students who completed both the pre- and the posttest. Furthermore, the same librarian taught all sessions of the active learning treatments to minimize the potential that treatment effects could be attributed to the mode of instruction.

There were no statistically significant differences in pre-test scores across the three groups. This supports an inference that randomization of the 22 public speaking sections yielded three groups of students with similar baseline information literacy proficiency. This suggests an equivalent 
starting point for our three groups and possibly for future Fall semester public speaking students, if they mirror this sample.

Results indicated that pre-test scores on information literacy measures differed based on class level, with the lowest scores attributed to first year students and the highest to seniors. This finding may highlight an unsurprising trajectory of cognitive growth throughout one's tenure in college. However, it may also demonstrate the potential for gains in early interventions in information literacy education given that students at all class levels showed statistically significant improvement in their scores.

These findings also suggest the promise of sustained course-library partnerships and integration of information literacy instruction across the curriculum and throughout one's college career. In terms of learning, a curriculum-integrated model of information literacy instruction would mean that 1) students learn about and practice information literacy during every semester of their college education; 2) information literacy instruction would both reinforce and develop students' previous knowledge; and 3) information literacy instruction would be adapted to the changing contexts of students' learning and course needs, consistent with critical communication pedagogy praxis (Fassett \& Warren, 2007). Such an integrated approach would facilitate the development of information literacy abilities and habits, such as comprehension, analysis and synthesis, evaluation, and creative application, aligning information literacy instruction to Bloom's taxonomy (Callister, 2010; Keene, Colvin, \& Sissons, 2010; Macpherson, 2004; Vitolo \& Coulston, 2002).

A challenge to implementing a curriculum-integrated model of information literacy instruction, and particularly one faced by general education courses, such as public speaking, is that these courses typically enroll students from a large variety of majors, making continuity of information literacy instruction beyond the course difficult. General education courses provide an excellent context for laying the foundation of information literacy, but it is also difficult to follow up with students and faculty in the individual majors. Similar to integrating writing across the curriculum, frameworks for information literacy (IL) have emerged, suggesting that a multidisciplinary information literacy work group is formed that 1) defines IL learning outcomes 2) interfaces with department heads and curriculum committees about possible library collaborations; and 3) provides contextualized guidance and frameworks for curriculum development (Wang, 2011).

Speaking to the potential for IL instruction to be contextualized to the goals and pedagogical approaches in different disciplines, the findings of this study suggest that various methods of instruction can lead to gains in information literacy. There was growth across all groups and instructional types: not only the seven sections in Library Instruction Method A and eight sections in Library Instruction Method B, all with the same librarian instructor and assigned instructional technique, but also the seven "control" sections with 5 different instructors and as many teaching techniques as instructors. The observation that the control group showed progress in test scores may be related to the fact that course instructors in those sections also chose to spend the session teaching information literacy, based on their own expertise and/or experiences with library-led instruction. Thus, this study was not a simple comparison of "treatment" versus "no treatment," and points to the overall value in information literacy instruction. 
Improvement across treatment groups likely indicates that student proficiency improved with information literacy instruction. An alternate hypothesis, that the post-test was "easier" and that student scores improved without any increase in actual proficiency, is not favored. The pre-test and post-test were deliberately designed as mirror tools, with questions similarly worded and generally only the topic (climate change in [state where university resides] versus tick-borne diseases) varied. Also, students were not given the answers to the pre-test before proceeding to the post-test, and did not see their pre-test scores. Thus, it is tentatively inferred that actual information literacy learning occurred, even in the control group. Further testing that reverses the sequence of pre- and post-test delivery would provide greater insight into this inference. At the same time, the study design measured short-term gains in information literacy competency and not retention and further development of these competencies in accordance with frameworks, such as Bloom's taxonomy. Developing and implementing a curriculum-integrated model of information literacy instruction would allow for the longitudinal assessment of both learning outcomes and pedagogical approaches.

The results of this study suggest that the librarian's role in information literacy instruction is essential. Notably, students' gains in information literacy competencies were higher when a librarian facilitated the instruction, for both library instruction methods. This statistical difference may point to the expertise a librarian brings to the classroom. It may also suggest that the librarian, who was integral in pairing the learning outcomes to the question design in the preand post-tests, was successful in teaching those concepts. This finding may present a 'train the trainers' opportunity wherein librarians can partner with instructors to co-create and teach information literacy.

Implementing such an opportunity is reflective of the framework proposed by Wang (2011). The design of both this study and the semester-long classroom instruction associated with it align with this framework on the smaller scale of a course-library partnership (instead of full curriculum integration within an academic major). The librarian and the course director worked and continue to work together to 1) identify IL learning outcomes linked to the overall learning goals of the course; 2) plan teaching/learning strategies - for both the library session and the course as a whole - that would facilitate students' achievement of these outcomes; 3) and align assignments and assessments with the identified IL learning outcomes.

The findings of this study further suggest that different teaching approaches can equally facilitate students' movement toward identified learning outcomes, and that the purposeful alignment of outcomes with instruction is more important than the (decontextualized) characteristics of the instructional approach itself. Whereas treatments A and B were designed to differ in the type of active learning employed in the classroom, the mode of instruction appears inconsequential to the improvement scores. The website evaluation activity elicited participation by students in both the scrutiny of websites and in subsequent small and large group discussions of their credibility (to the extent that students were willing to engage with the material). The play activity engaged all participants in some way from the beginning (even if only standing in the circle and passing the ball) and facilitated a different kind of engagement through kinesthetic activity and dialogue, but without specific sources to critique for reliability indicators. Noticeable with the play activity was that although everyone was ostensibly participating, there was the possibility for fewer 
students to respond to discussion questions if they were primarily being answered by those who ended up with the ball in hand (this can be addressed through additional prompting by the instructor). Even though the types of participation were different in each treatment, the commonality that the students were active suggests a sufficiently strong effect as to render the two treatment outcomes, on average, similar.

Overall, the finding that the type of active learning technique did not make a difference in cognitive measures of IL suggests that either active learning option is viable for improving information literacy learning and is subject to instructor preference. Moreover, the findings from this study restrain the excitement that many have for games (or play) as transformative in teaching (Brinker et al., 2014; NERCOMP, 2018; Stirling, 2013). That said, it is possible that other types of games would differentially affect learning outcomes, or that domains of learning outside of cognitive outcomes alone would demonstrate different findings with the play technique used in this study. Given the design of the present study, we cannot assess, beyond the anecdotal, if enjoyment of the play activity occurred and if affective experiences were correlated with cognitive learning in IL. To consider such possible links, future research could include measures associated with the affective domain in Bloom's taxonomy (e.g., Pierre \& Oughton, 2007).

\section{Limitations and Future Directions}

As mentioned earlier, this study reports on a subset of data, collected as part of a larger project. Measures of information literacy, public speaking competencies, and civic engagement attitudes were administered at the beginning and at the end of each semester. Subsequent articles will include analysis of these data and provide a more complete picture of students' learning outcomes over the course of the semester, considering the integrated model of information literacy instruction. The present study reports only on a comparison between single-session active learning techniques for information literacy instruction.

The instrument used in this study was designed by the authors and was not previously validated. However, as mentioned earlier, the instrument was developed based on existing frameworks for information literacy. The instrument was piloted in this study and will likely be used in forthcoming research after revisions (see the Appendix for more information on future modifications). The pre-test was administered at a class session prior to information literacy instruction, and serves as a baseline for content knowledge. The post-test was administered immediately following information literacy instruction. It serves as a measure of short-term learning and does not assess long-term knowledge acquisition and retention.

This study took place at a rural, predominantly white, land and sea grant university, and thus demonstrates the constraints that are intrinsic to any one setting. Along those lines, this study examined one type of course, and thus might benefit from a broader subset of the student population within and outside this university.

This study reported quantitative measures, and primarily sought quantitative results, which does not fully explain student experiences or learning. Opportunities for future research include qualitative analysis of learning artifacts, such as homework assignments, worksheets, or other learning objects used in the classroom. Further research would also benefit from considering 
measures of student outcomes in the affective domain, particularly as this might touch upon further motivations for and interest in developing one's information literacy competencies (Pierre \& Oughton, 2007).

\section{Conclusion}

According to Riehle and Weiner (2013), high-impact educational practices "often include active, contextual pedagogies, span the college experience, and engage students in the learning process" (p. 134). At the same time, recent considerations of active learning critique a preoccupation with "collecting, selecting, and implementing techniques" (Weimer, 2018, n.p.) instead of considering student processes of discovery and engagement. The present study supports the claim that active learning positively affects students' cognitive gains in information literacy. At the same time, results of the study suggest that the type of active learning approach makes no difference. This can be helpful to librarians and instructors in highlighting that, as long as active learning is approached with clearly-defined learning outcomes in mind (here, we were guided by the ACRL Framework), the choice of technique itself is not so consequential.

The results of this study also suggest that what is more important than the type of active learning technique is that information literacy instruction is integrated meaningfully into the curriculum. In this study, it made a significant difference in students' learning if IL was taught by a librarian or by the course instructor. Librarians are uniquely prepared to address, engage, and teach about the complexities of information literacy in today's content-saturated context. As discussed earlier, this suggests their integral role in developing purposeful and multi-disciplinary integration of information literacy instruction across the curriculum, including the development of online modules, train-the-trainer opportunities, and related assessment efforts (e.g., Wang, 2011).

As hands-on activities continue to gain momentum as preferred teaching methods, and as the gamification of the classroom grows in popularity, it is incumbent upon instructors to examine the effects of specific teaching methods on student learning, engagement, outcomes, and objectives. This study attempted to discern differences in the development of information literacy based on discrete active learning exercises that were tailored to a suite of public speaking courses. Future research plans include an expansion of the cognitive focus of this study to consider affective domains of learning, as well as the application of qualitative methodologies to better understand IL learning in the public speaking classroom. In addition, the authors plan to explore the addition of online elements to IL integration in the public speaking curriculum, and test the differences, if any, to classroom teaching. In this vein, we will 'play on,' and continue to explore the possibilities for and contexts of teaching, learning, and applying critical information literacy. 


\section{References}

Benjes-Small, C. \& Dunn, B. (2017, January 22). Information literacy and fake news. ACRLog. Retrieved from http://acrlog.org/2017/01/22/information-literacy-and-fake-news/

Benjes-Small, C. \& Tucker, K. (2013). Keeping up with...flipped classrooms. Retrieved from http://www.ala.org/acrl/publications/keeping_up_with/flipped_classrooms

Bonwell, C. C., \& Eison, J. A. (1991). Active Learning: Creating Excitement in the Classroom. 1991 ASHE-ERIC Higher Education Reports. Washington, DC: ERIC Clearinghouse on Higher Education.

Bowden, E. (2017). Keeping up with... debiasing and fake news. Retrieved from http://www.ala.org/acrl/publications/keeping_up_with/debiasing

Brinker, J. K., Roberts, P., \& Radnidge, B. (2014). The game of late life: a novel education activity for the psychology of ageing. Educational Gerontology, 40(2), 91-101.

Callister, P. D. (2010). Time to blossom: An inquiry into Bloom's taxonomy as a hierarchy and means for teaching legal research skills. Law Library Journal, 102, 191-219. doi: $10.2139 /$ ssrn. 1488918

Detlor, B., Booker, L., Serenko, A., \& Julien, H. (2012). Student perceptions of information literacy instruction: The importance of active learning. Education for information, 29, 147-161. doi: 10.3233/EFI-2012-0924

Dugard, P., \& Todman, J. (1995). Analysis of pre-test-post-test control group designs in educational research. Educational Psychology, 15, 181-198.

Elmborg, J. (2006). Critical information literacy: Implications for instructional practice. Journal of Academic Librarianship, 32(2), 192-199. http://dx.doi.org/10.1016/j.acalib.2005.12.004

Fake news. (2017). Retrieved from http://sandbox.acrl.org/tags/fake-news

Fassett, D. L., \& Warren, J. T. (2007). Critical communication pedagogy. Thousand Oaks, CA: Sage.

Fassett, D. L., \& Warren, J. T. (2008). Pedagogy of Relevance: A Critical Communication Pedagogy Agenda for the 'Basic' Course. Basic Communication Course Annual, 20(1), 6.

Faust, J. L., \& Paulson, D. R. (1998). Active learning in the college classroom. Journal on excellence in college teaching, 9(2), 3-24.

Fisher, M., Cox, J.W., \& Herman, P. (2016, December 6). Pizzagate: From rumor, to hashtag, to gunfire in D.C. Washington Post. Retrieved from https://www.washingtonpost.com/local/pizzagate-from-rumor-to-hashtag-to-gunfire-indc/2016/12/06/4c7def50-bbd4-11e6-94ac-

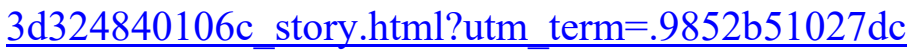


Free, D. (2017). ACRL Framework for Information Literacy Toolkit Launches. Retrieved from http://www.acrl.ala.org/acrlinsider/archives/14048

Freeman, S., Eddy, S. L., McDonough, M., Smith, M. K., Okoroafor, N., Jordt, H., \& Wenderoth, M. P. (2014). Active learning increases student performance in science, engineering, and mathematics. Proceedings of the National Academy of Sciences, 111, 8410-8415. doi: https://doi.org/10.1073/pnas.1319030111

Gersch, B., Lampner, W., \& Turner, D. (2016). Collaborative metaliteracy: Putting the new information literacy framework into (digital) practice. Journal of Library \& Information Services in Distance Learning, 10, 199-214. doi: https://doi.org/10.1080/1533290X.2016.1206788

Herakova, L., Bonnet, J., \& Congdon Jr, M. (2017). Centering Information Literacy (as) Skills and Civic Engagement in the Basic Communication Course: An Integrated Course Library Collaboration. Basic Communication Course Annual, 29(1), 12.

Higgins, K. (2016, November 28). Post-truth: a guide for the perplexed. Nature. Retrieved from http://www.nature.com/news/post-truth-a-guide-for-the-perplexed-1.21054

Hoppe, B. (2017). Beach balls, Play-Doh and Plato: Play as critical pedagogy. Presentation at [state where university resides] Academic Libraries Day in Waterville, [state where university resides]. Retrieved from https://prezi.com/view/ygfPRejCIimxolxUn4WN/

Hunt, S. K., Simonds, C. J., \& Simonds, B. K. (2009). Uniquely qualified, distinctively competent: Delivering 21st century skills in the basic course. Basic Communication Course Annual, 21, 1-29.

Jazynka, K. (2017, April 6). Colleges turn 'fake news' epidemic into a teachable moment. Washington Post. Retrieved from https://www.washingtonpost.com/lifestyle/magazine/colleges-turn-fake-news-epidemicinto-a-teachable-moment/2017/04/04/04114436-fd30-11e6-99b49e613afeb09f_story.html?utm term $=.24 \mathrm{~d} 7 \mathrm{~b} 534 \mathrm{f} 30 \mathrm{e}$

Johnson, H. A., \& Barrett, L. C. (2017). Your teaching strategy matters: how engagement impacts application in health information literacy instruction. Journal of the Medical Library Association, 105, 44-48. doi:10.5195/jmla.2017.8

Keene, J., Colvin, J., \& Sissons J. (2010). Mapping student information literacy activity against Bloom's Taxonomy of Cognitive Skills. Journal of Information Literacy, 4, 5-17. doi: http://dx.doi.org/10.11645/4.1.189

Khailova, L. (2017). Flipping library information literacy sessions to maximize student active learning: toward articulating effective design and implementation principles. Reference \& User Services Quarterly, 56, 150-155. doi: http://dx.doi.org/10.5860/rusq.56n3.150 
Macpherson, K. (2004). Undergraduate information literacy: A teaching framework. Australian Academic \& Research Libraries, 35, 226-241. doi: 10.1080/00048623.2004.10755273

Margino, M. (2013). Revitalizing traditional information literacy instruction: Exploring games in academic libraries. Public Services Quarterly, 9, 333-341. doi: https://doi.org/10.1080/15228959.2013.842417

Meriam Library (2010). Evaluating information: Applying the CRAAP test. Chico, CA: California State University. Retrieved from https://www.csuchico.edu/lins/handouts/eval_websites.pdf

Meyer, K. R., Hunt, S. K., Hopper, K. M., Thakkar, K. V., Tsoubakopoulos, \& Van Hoose, K. J. (2008). Assessing information literacy in the basic communication course. Communication Teacher, 22, 22-34. doi: 10.1080/17404620801926925

National Communication Association (2015). What should a graduate with a communication degree know, understand, and be able to do?: The National Communication Association's learning outcomes in communication project. Retrieved from https://www.natcom.org/sites/default/files/publications/LOC_1_What Should a Graduat e with a Communication Degree.pdf

NERCOMP (NorthEast Regional Computing Program). (2018). Game-based learning: The magic door to a transformative student experience. Presentation at the NorthEast Regional Computing Program Annual Conference. Retrieved from https://events.educause.edu/special-topic-events/nercomp-annualconference/2018/agenda/gamebased-learning-the-magic-door-to-a-transformativestudent-experience

Nielsen, J., \& Jetton, L. L. (2017). Assessing the effectiveness of collaborative subject-specific library instruction. Qualitative and Quantitative Methods in Libraries, 3, 343-350.

Oakleaf, M. (2014). A roadmap for assessing student learning using the new framework for information literacy for higher education. The Journal of Academic Librarianship, 5, 510-514. doi: http://dx.doi.org/10.1016/j.acalib.2014.08.001

Oxford Dictionaries. (2016). Oxford dictionaries word of the year 2016 is... Retrieved from https://en.oxforddictionaries.com/word-of-the-year/word-ofthe-year-2016

Prince, M. (2004). Does active learning work? A review of the research. Journal of Engineering Education, 93, 223-231. doi: 10.1002/j.2168-9830.2004.tb00809.x

Riehle, C. F., \& Weiner, S. A. (2013). High-impact educational practices: An exploration of the role of information literacy. College \& Undergraduate Libraries, 20, 127-143. doi: https://doi.org/10.1080/10691316.2013.789658 
Rockenbach, B. (2011). Archives, undergraduates, and inquiry-based learning: Case studies from Yale University Library. The American Archivist, 74, 297-311. doi: https://doi.org/10.17723/aarc.74.1.mml4871x2365j265

Rustic, A. E., \& Wood, J. K. (2018). Increasing information literacy with a librarian as the class research mentor. Communication Teacher. doi: 10.1080/17404622.2017.1372613

Rutenberg, J. (2016, November 6). Media's next challenge: Overcoming the threat of fake news. New York Times. Retrieved from https://www.nytimes.com/2016/11/07/business/media/medias-next-challengeovercoming-the-threat-of-fake-news.html

Simmons, M. H. (2005). Librarians as disciplinary discourse mediators: Using genre theory to move toward critical information literacy. portal: Libraries and the Academy, 297-311. doi: 10.1353/pla.2005.0041

Sjoberg, L. M., \& Ahlfeldt, S. L. (2010). Bridging the gap: Integrating information literacy into communication courses. Communication Teacher, 24, 131-135.

doi:10.1080/17404622.2010.489193

Shao, C., Ciampaglia, G.L., Varol, O., Flammini, A., \& Menczer, F. (2017). The spread of fake news by social bots. Retrieved from https://arxiv.org/abs/1707.07592

Smith, L. (2013). Towards a model of critical information literacy instruction for the development of political agency. Journal of Information Literacy, 7, 15-32. doi: 10.11645/7.2.1809

Stanford History Education Group. (2016). Evaluating information: The cornerstone of civic online reasoning. Retrieved from

https://sheg.stanford.edu/upload/V3LessonPlans/Executive\%20Summary\%20 11.21.16.pdf

Stirling, D. (2013). Games as educational tools: Teaching skills, transforming thoughts.

Retrieved from https://ischool.syr.edu/infospace/2013/06/27/games-as-educational-toolsteaching-skills-transforming-thoughts

Tewell, E. C., \& Angell, K. (2015). Far from a trivial pursuit: assessing the effectiveness of games in information literacy instruction. Evidence Based Library and Information Practice, 10, 20-33. doi: http://dx.doi.org/10.18438/B8B60X

Valenzano III, J., Wallace, S. P., \& Morreale, S. (2014). Consistency and change: The (r)evolution of the basic communication course. Communication Education, 63, 355-365. doi: $10.1080 / 03634523.2014 .911928$

van Breukelen, G. J. (2013). ANCOVA versus CHANGE from baseline in nonrandomized studies: The difference. Multivariate Behavioral Research, 48(6), 895-922.

Vitolo, T. M., \& Coulston, C. (2002). Taxonomy of information literacy competencies. Journal of Information Technology Education, 1, 43-51. doi: 10.28945/343 
Walsh, A., \& Inala, P. (2010). Active learning techniques for librarians: Practical examples. Oxford, UK: Chandos.

Wang, L. (2011). An information literacy integration model and its application in higher education. Reference Services Review, 39, 703-720. doi: https://doi.org/10.1108/00907321111186703

Weaver, K. D., \& Pier, P. M. (2010). Embedded information literacy in the basic oral communication course: From conception through assessment. Public Services Quarterly, 6, 259-270. doi: 10.1080/15228959.2010.497455

Weimer, M. (2018, February 28). Deeper thinking about active learning. Retrieved from https://www.facultyfocus.com/articles/teaching-professor-blog/deeper-thinking-activelearning

Wenger, K. (2014). Problem-based learning and information literacy: A natural partnership. Pennsylvania libraries: Research and practice, 2, 142-154. doi: 10.5195/palrap.2014.61

Young, J. (2016). Can library research be fun? Using games for Information Literacy Instruction in Higher Education, Georgia Library Quarterly, 53. Retrieved from http://digitalcommons.kennesaw.edu/glq/vol53/iss3/7 


\section{Appendix}

Below are the quantitative questions used in this study, followed by the evaluative concept(s) associated with each question. Additionally, we have included two questions that proved problematic and were removed from the analysis.

\section{Question 2 (relevance/fit of source to evidence sought)}

Pre-test: What are you most likely to find in a news article when researching your topic?

1. A bibliography on climate science.

2. Firsthand accounts from people in the ski industry who are affected by climate change.

3. Technical terms on the economics of the ski industry.

4. Historical analysis of climatology and the ski industry.

Post-test: What are you most likely to find in a journal article when researching this topic?

1. Discussion of current outbreaks in New England

2. Statistics about the long-term spread of Lyme disease across New England

3. Brief profiles of people with Lyme disease

4. Descriptions of tick-borne illnesses in easily understandable language

\section{Question 3 (relevance/fit of source to evidence sought)}

Pre-test: What is least likely to be true about a government report entitled, "New England Snowfall Statistics from 2010 to 2015 "?*

1. It was written by experts on skiing techniques.

2. There are few sources to support the author's claims.

3. The target audience is the general public.

4. The report can be obtained by Fogler Library.

*Question 3 in the pre-test had two correct answers (bullets 1 and 2), although the intention was to only have one. This will be corrected in future testing.

Post-test: What is most likely true about a peer-reviewed journal article titled, "A longitudinal study of the effect of tick-borne diseases on New England farming"?

1. It was written by experts on animal health.

2. There are few sources to support the author's claims.

3. The target audience is the general public.

4. The article cannot be obtained by Fogler Library.

\section{Question 4 (source evaluation)}

Pre-test: The journal article, "Effects of warmer temperatures on ski season duration in rural [state where university resides]," would appear less credible if:

1. The author has a Nova Scotia office address.

2. The research was funded by the [state where university resides] Ski Advocacy Association.

3. The article costs $\$ 30$ to access through a paywall.

4. The same information can be found in multiple, reputable places.

Post-test: A tweet about tick borne illnesses in New England would appear more credible if: 
1. It is from a farmer in [state where university resides].

2. It is from a pesticide company.

3. It links to an article that costs $\$ 30$ to access.

4. The information can be found in multiple, reputable places.

\section{Question 5 (authority; source evaluation)}

Pre-test: A person is most likely an expert on your topic if:

1. She has a PhD in communication sciences and disorders.

2. Her documents use terms such as "post-climate future," "photovoltaics," and "dynamic change."

3. She has published articles and book chapters on climate science, including "A longitudinal study of New England warming trends."

4. She has a website called, "Climate Change and You."

Post-test: A person is most likely an expert on tick-borne illness if:

1. She is a reporter for National Public Radio.

2. She has a $\mathrm{PhD}$ in English.

3. She is an entomologist who blogs about her research.

4. She donates money to the Anti-Lyme Disease campaign.

\section{Question 6 (purpose/source evaluation; relevance/fit of source to evidence sought)}

Pre-test: What are you most likely to find on the Sugarloaf Ski Resort website about your topic?

1. A description of snow conditions that you could compare to those at other resorts in different climates.

2. Impartial information about climate change effects on skiing that could be compared to similar information from other resorts.

3. A warning to the public about the dangers of skiing too often.

4. A list of relevant resources on the impact of climate change on slope conditions. Post-test: What are you most likely to find on Tick Extermination Station's website, "Guide to Tick Borne Diseases and How to Eradicate Them at the Source":

1. A description of the effects of tick borne diseases on the general public.

2. Impartial information about tick-eating wildlife.

3. Guidance to the public about the benefits of tick populations.

4. A list of relevant resources on the role of ticks in controlling the population of deer.

\section{Question 7 (relevance/fit of source to evidence sought)}

Pre-test: What source is least likely to report firsthand experiences of snowmakers at [state where university resides]'s ski resorts in 2017 ?

1. Ski resort's commercial website

2. News article

3. Tweet from a ski resort

4. Journal article

Post-test: What source is most likely to report recent firsthand experiences of people who are infected with Lyme Disease?

1. [state where university resides] Tourism website

2. News article

3. Tweet from a scholar 


\section{Journal article}

\section{Question 8 (relevance/fit of source to evidence sought)}

Pre-test: What source is most likely to include a comparison of climate change adaptation strategies at ski resorts throughout New England?

1. Ski resort's commercial website

2. News article

3. Tweet from a ski resort

4. Journal article

Post-test: What source is most likely to include a multi-year analysis of disease mitigation strategies in tick prone areas throughout New England?

1. [state where university resides] Tourism website

2. News article

3. Tweet from a hiker in New England

4. Journal article

\section{Question 9 (relevance/purpose/fit of source to evidence sought)}

Pre-test: What source is least likely to point to additional literature on [state where university resides]'s changing climate?

1. Ski resort's commercial website

2. News article

3. Tweet from a scholar

4. Journal article

Post-test: What source is least likely to point to additional literature on the effects of tick borne illnesses on New England tourism?

1. [state where university resides] Tourism website

2. News article

3. Tweet from a scholar

4. Journal article

Question 10 (purpose; source evaluation; relevance/fit of source to evidence sought) Pre-test: Who would represent the target audience for a scholarly journal about climate science?

- Professors and researchers

- Master gardeners

- Farmers and ranchers

- Coastal homeowners

Post-test: Who would represent the target audience for the Journal of Ticks and Tick-borne Diseases?

- Pet owners

- People who study veterinary and human medicine

- Concerned parents of a child bitten by a tick

- Bug and animal enthusiasts

On both tests, Question 10 was not included in data analysis due to identified incomparability between pre-test and post-test versions of the question. Specifically, the pre-test question asked the student to identify the target audience for a "scholarly journal", whereas the post-test 
question asked the student to identify the target audience for a specific journal title. Because the pre-test question provided a cue (i.e., "scholarly") that the post-test question did not, for data analysis we considered the two questions incomparable. Indeed, a separate analysis indicated that students tended to answer the pre-test version of Q10 accurately more often than the post-test version. Also of note, Question 10, in both the pre- and post-tests, allowed for multiple answers, given the experience of the authors that students often consider lay people the primary audience for scholarly journal articles. While we find this question compelling, we dropped it from the analysis after all students showed a drop in scores, which we hypothesize is due to the differential wording. Thus, a revised question for future surveys in the course will present an image of a scholarly article for each scenario topic so that the questions more accurately depict the item to which the test refers. This will make the two questions more precise and better mirror one another.

\section{Question 11 (currency/source evaluation)}

Pre-test: You decide to compare snowmaking infrastructure in the late 1990s versus 2017. Is it ok to include a source from 1998? Explain your answer.

Post-test: You decide to compare cutting edge medical treatments for tick-borne illnesses in New England. Are you likely to include a source from 1998? Explain your answer.

Question 11 was removed from data analysis since it included an open-ended question aimed at deriving students' rationale for their answer and thus, there was not a fixed answer. 